\title{
ポリイソブチレンの滃透壓法に依る 分子量测定
}

中鸟章夫

要 旨

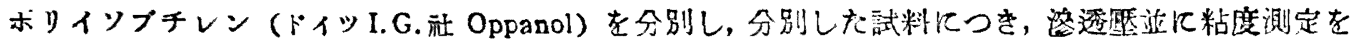

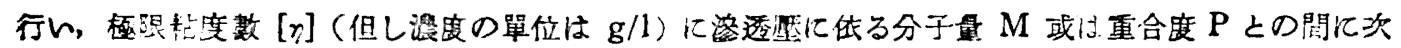
の關係の成立する事を明にした。

$$
\begin{aligned}
& {[\eta]=3.98 \times 10^{-4} \cdot \mathrm{F}^{0.76}} \\
& {[\eta]=20.6 \times 10^{-6} \cdot \mathrm{M}^{0.74}}
\end{aligned}
$$

\section{粕管}

ポリイソフチレンは次のような棒造をもつ炭化水素であり<smiles>CCC(C)(C)CC(C)(C)CC(C)(C)CC(C)(C)C</smiles>

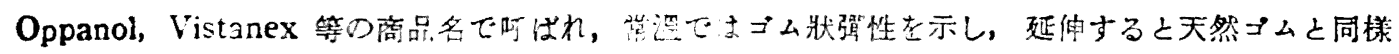

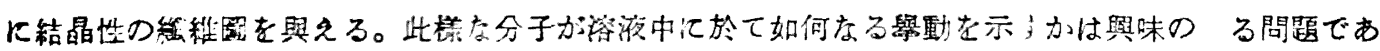

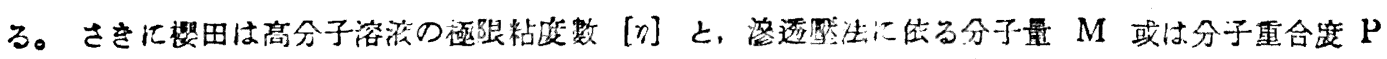

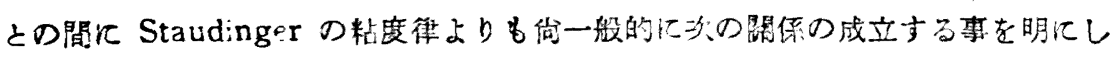

$$
[\eta]=K \cdot P^{\mathbf{n}_{1}}
$$

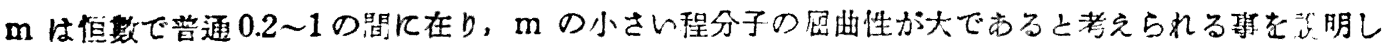
ね"。

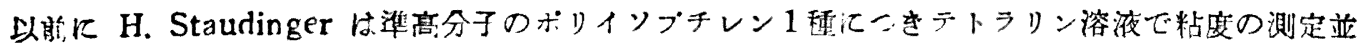

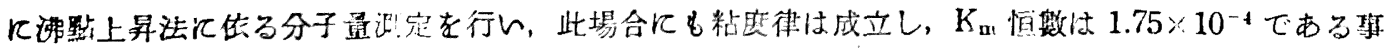

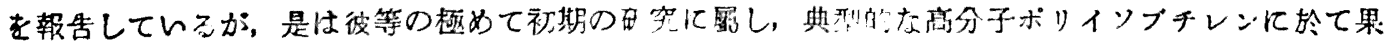

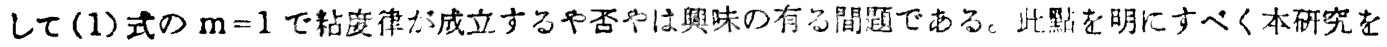
行つた。

\section{宽駩及結果}

試 料

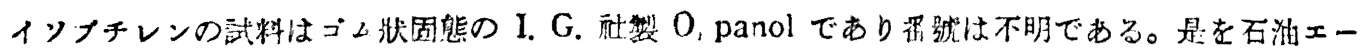
テルに溶解し，ナセトンを更えて分别沈溉を行い，数個のフラクションに分けた。 


\section{济透照测定}

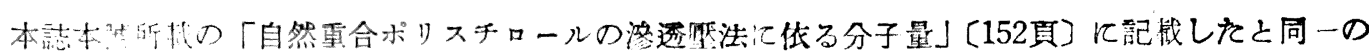

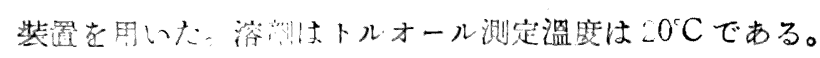

\section{分子是の部第}

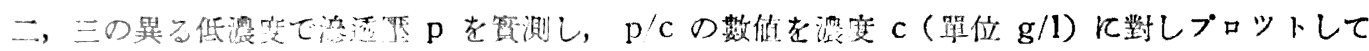

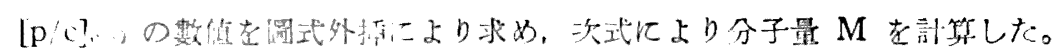

$$
\left[P^{\prime} C_{-\rightarrow 0}^{\top}=\begin{array}{l}
R T \\
M
\end{array}\right.
$$

基本分于た法うごするから $\mathrm{M} / 53$ は重合度 $\mathrm{P}$ 索與える。

1. $300,2 \pi$

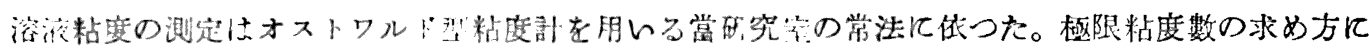

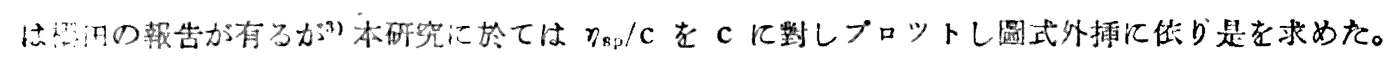

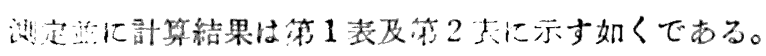

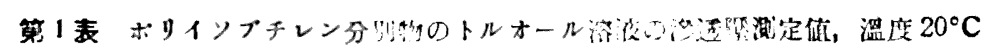

\begin{tabular}{|c|c|c|c|c|c|}
\hline \multicolumn{2}{|c|}{ フラクション罦踠 } & 致度 $\mathrm{c} \mathrm{g} / \mathrm{l}$ & 透跃 $\mathrm{p} \mathrm{cm}$ & $\mathrm{p} / \mathrm{c}$ & 昫 \\
\hline \multirow{3}{*}{ Fr. } & \multirow{3}{*}{ I } & 2.00 & 0.10 & 0.050 & {$[\mathrm{p} / \mathrm{c}]_{\mathrm{c} \rightarrow 0}=0.044$} \\
\hline & & 4.92 & 0.30 & c.061 & \multirow{2}{*}{$P=11625$} \\
\hline & & 9.64 & $(1.08)$ & $(0.112)$ & \\
\hline \multirow{3}{*}{ Fr. } & \multirow{3}{*}{ II } & 2.57 & 0.14 & 0.055 & {$[p / c]_{c \rightarrow 0}=0.048$} \\
\hline & & $\therefore, 94$ & 0.35 & 0.071 & \multirow{2}{*}{$P=10657$} \\
\hline & & 9.40 & 1.00 & 0.138 & \\
\hline Fr. & II $^{\prime}$ & 2.24 & 0.16 & 0.071 & $P=7869$ \\
\hline \multirow{3}{*}{$F_{5}$} & \multirow{3}{*}{ III } & 3.15 & 0.28 & 0.088 & {$[\mathrm{p} / \mathrm{c}]_{\mathrm{c} \rightarrow 0}=0.078$} \\
\hline & & 4.5 & 0.69 & 0.099 & \multirow{2}{*}{$P=65 \pi 8$} \\
\hline & & $1^{110 .}$ & 1.28 & 0.28 & \\
\hline \multirow{4}{*}{ Fr. } & \multirow{4}{*}{ IV } & $2 . x_{1}$ & 0.47 & 0.157 & {$[p / c]_{c \rightarrow 0}=0.150$} \\
\hline & & $3.0 \mathrm{~s}$ & 0.48 & 0.156 & \multirow{3}{*}{$\mathrm{P}=3410$} \\
\hline & & 4.98 & 0.80 & 0.161 & \\
\hline & & 9.25 & 1.58 & 0.171 & \\
\hline \multirow{2}{*}{ Fr. } & \multirow{2}{*}{ V } & 1.29 & 0.20 & 0.155 & {$[p / c]_{c \rightarrow 0}=0.152$} \\
\hline & & 6.25 & 1.04 & 0.170 & $P=3365$ \\
\hline
\end{tabular}

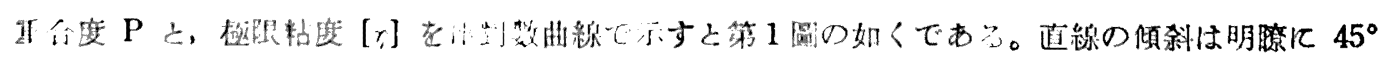
ではない。したがつて（1）式の $\mathrm{m}$ は 1 でなくStaudingerの粘度律は成立しなん。計算結果 $\mathrm{m}=0.74$

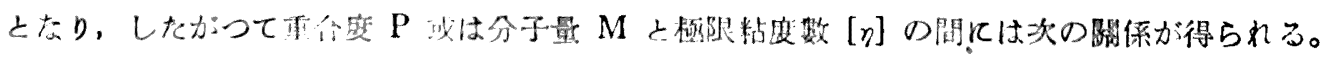

$$
\begin{aligned}
& {[\eta]=3.93 \times 10^{-4} \cdot \mathrm{P}^{017}} \\
& {[\eta]=20.2 ; \times 10^{-6} \cdot \mathrm{M}^{174}}
\end{aligned}
$$

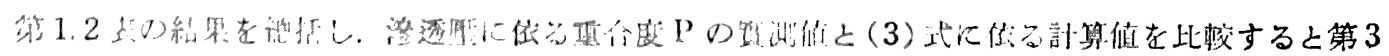

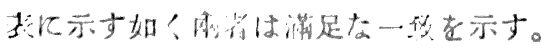




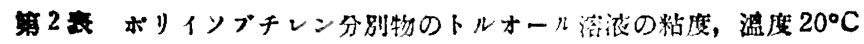

\begin{tabular}{|c|c|c|c|c|c|c|}
\hline フタクショ & ヨン番號 & 搌度 c g/l & $r_{\text {rel }}$ & $r_{\mathrm{s} n} / \mathrm{c}$ & $\left(\ln \dot{\eta}_{\mathrm{r} \theta} !\right) / \mathrm{c}$ & {$[\eta]$} \\
\hline & & 1.45 & 1.8004 & 0.552 & 0.392 & 0.400 \\
\hline Fr. & I & 2.90 & 3.0746 & 0.715 & 0.385 & \\
\hline & & 4.38 & $5.129 !$ & 0.943 & 0.373 & \\
\hline & & 1.285 & 1.6428 & 0.02 & 0.384 & 0.376 \\
\hline Fr. & II & 2.57 & $2.6 ? 1$ & $0: \therefore 5$ & 0.376 & \\
\hline & & 4.14 & 4.2913 & 0.795 & 0.351 & \\
\hline $\mathrm{Fr}_{r}$ & II' & 1.00 & 1.3350 & 0.335 & 0.288 & 0.290 \\
\hline N1. & & 3.02 & 2.3499 & 0.447 & 0.283 & \\
\hline & 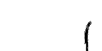 & 1.5 .5 & $1.5 \lg 8$ & 0.330 & 0.265 & $0.26 ?$ \\
\hline Fr. & III & 3.15 & 2.2917 & 0.410 & 0.255 & \\
\hline & & $4.9 j$ & 3.3815 & 0.481 & 0.218 & \\
\hline & & 1.14 & 1.2567 & 0.178 & 0.159 & 0.165 \\
\hline Fr. & IV & $2 . S s$ & 1.5614 & 0.195 & 0.155 & \\
\hline & & 5.10 & 2.160 & 0.223 & 0.119 & \\
\hline & & 0.70 & 1.1075 & 0.154 & 0.146 & 0.150 \\
\hline Fr. & $\mathbf{V}$ & 1.40 & 1.2303 & 0.165 & 0.148 & \\
\hline & ( & 3.10 & 1.5425 & 0.175 & 0.140 & \\
\hline
\end{tabular}

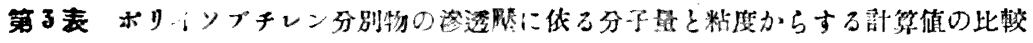

\begin{tabular}{|c|c|c|c|}
\hline フラクション苝能: & $P($ 唀限) & {$[\eta]$} & $\mathrm{P}$ (粘度より尌算 \\
\hline I & $1162 j$ & 0.400 & 11400 \\
\hline II & 10657 & 0.376 & 10470 \\
\hline II' & 7869 & 0.290 & $7: 80$ \\
\hline III & 6558 & 0.262 & 6380 \\
\hline $\mathrm{N}$ & 3410 & 0.165 & 3430 \\
\hline$y^{\prime}$ & $396 \pi$ & 0.150 & 3007 \\
\hline
\end{tabular}

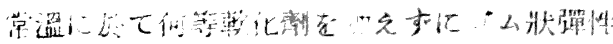

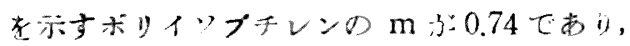

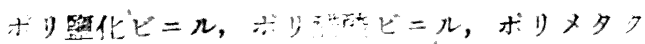
リル酸メチ几等上りむしろたですり，其意时で

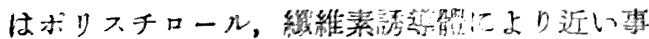

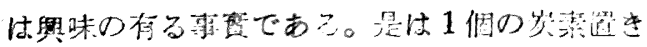
几存在する2殹ずつの側鎖 $\mathrm{CH}_{3}$ が屈曲を级害 して上却のビニル化合物よりも屈曲し能々菒に

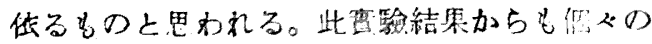

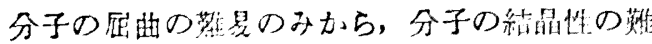

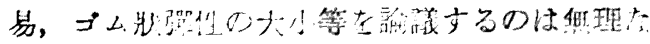
事は明である。

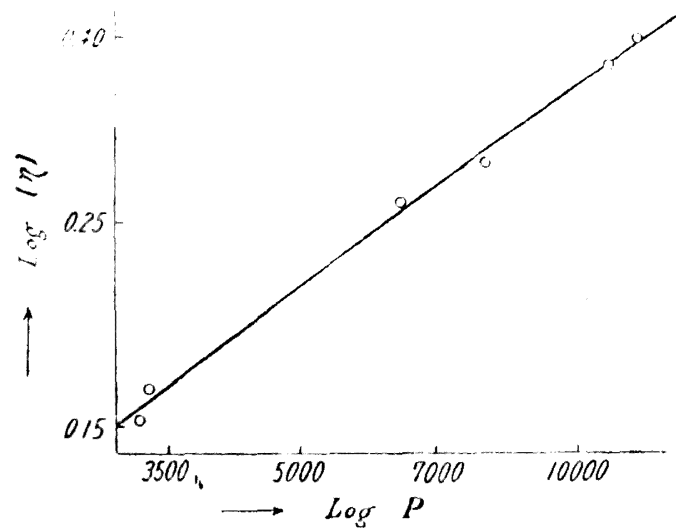

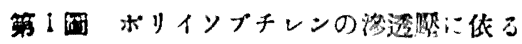

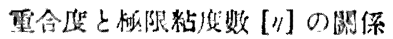

逓敦 1 . 


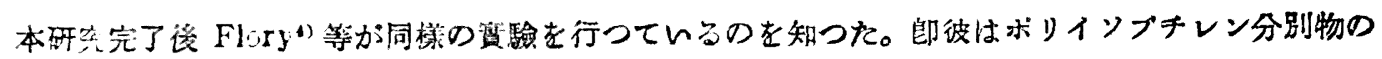

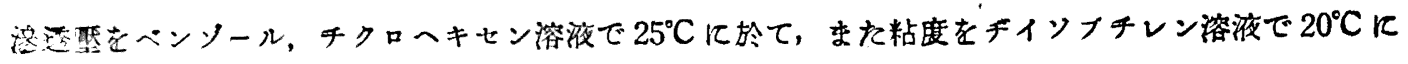
於て测定し，分子量之碮限粘度数の間沉次の關係の成立する事を見出した。

$$
[\eta]=3.60 \times 10^{-4} \mathrm{M}^{0.64}
$$

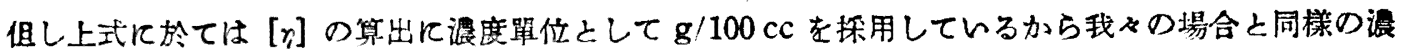
度單位 $\mathrm{g} / 1$ に改める之次の如くになる。

$$
\begin{aligned}
& {[\eta] 4.72 \times 10^{-4} \mathrm{P}^{0.64}} \\
& {[\eta]=36.0 \times 10^{-6} \mathrm{M}^{n .64}}
\end{aligned}
$$

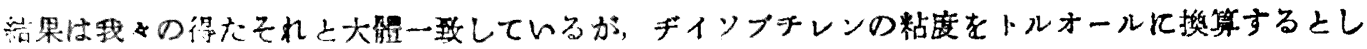

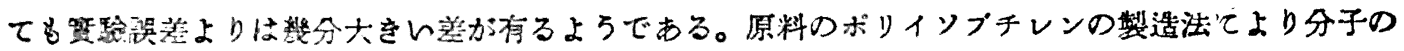

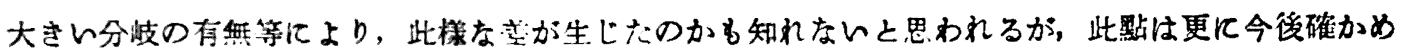
たん゙之思5。

\section{追 跑 2 .}

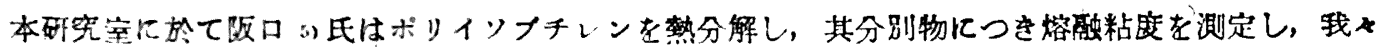

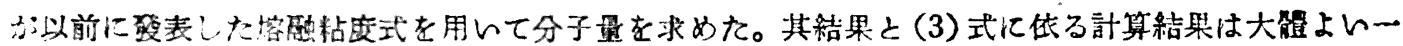
玟を示す。此事に閣しては近く别に報告される筈である。

\section{* 4}

1) 极田, 化绕触, 昭15，1940, 5, 33.

2) H. Staudinger, Helv. 1930, 13, 1375

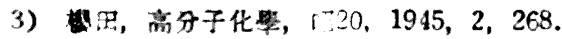

4) Flory, J. A.C.S. 1943, 65, 372.

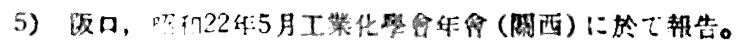

\section{財圈法人高分子化興協會昭和23年度收支豫算}

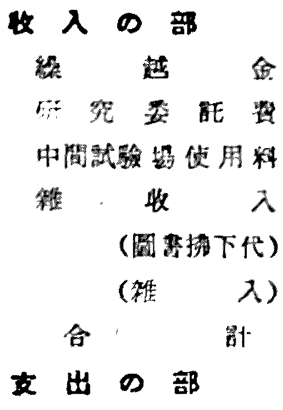

本所委员合

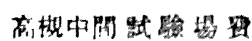

$$
\begin{array}{r}
213,{ }^{\prime} 98.12 \\
610,00.00 \\
240,000.00 \\
80,00.00 \\
(26,000.00) \\
(54,000.00) \\
1,133,198.12
\end{array}
$$

$170,000.00$

$100,00 r .00$

$20,000.00$
京都研笕空

大阪研究室怘

大阙山研强空理

本解研究室

研究助成 政

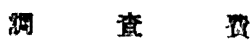

出版裂

退倳手當程立金

理储

全 别

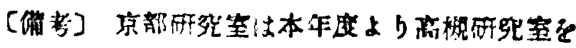
併合した。
350,00000

90,00000

$120,000.10$

$50,000.00$

$30,000.00$

$50,000.00$

$50,000.00$

$50,000.00$

$53,198.12$

$1,133,198.1$ ? 